\section{FEATURE}

Nicholas Palmer, Matthew Hughes

\section{Office for National Statistics}

\title{
Labour Force \\ Survey: reweighting and seasonal adjustment review 2008
}

\section{SUMMARY}

On 14 May 2008, the Office for National Statistics published national and regional Labour Force Survey (LFS) aggregate estimates that are consistent with reweighted LFS microdata. This article explains the revisions to the LFS aggregate estimates for 1992 to 2007 arising from the reweighting exercise and the annual seasonal adjustment review. The tables and charts in this article compare the differences between the LFS aggregate estimates and LFS microdata followed by a summary of how the reweighting and seasonal adjustment recommendations impacted on the headline labour market indicators. Analysis is also provided of the revisions to the population estimates and headline labour market indicators by Government Office Region.
( n 14 May 2008, the Office for National Statistics (ONS) published the regular monthly Labour Market Statistics First Release which contained Labour Force Survey (LFS) aggregate estimates that are consistent with reweighted LFS microdata. The reweighting means both the published LFS aggregate estimates and the LFS microdata, used for detailed analyses, are in line with the most recently published official population estimates and projections.

In order to put the latest reweighted data into context, this article provides:

- definitions of the LFS aggregate estimates and LFS microdata

- a description of the methodological changes made at the same time as the reweighting

- a summary of the revisions to the previously published LFS national and regional aggregate estimates and microdata

- details of the 2008 seasonal adjustment review recommendations, and

- a timetable for the release of the remaining reweighted LFS outputs and plans for future LFS reweighting

\section{Defining the LFS aggregate} estimates and microdata

The LFS aggregate estimates in the UK and regional Labour Market Statistics First Release are key labour market indicators, for example, the levels and rates of employment, unemployment and economic inactivity. They are derived from the LFS microdata and are calculated for any period of three consecutive months. These are referred to as three-month rolling averages - averages for January to March, February to April, and so on. The aggregate estimates are seasonally adjusted.

LFS microdata are quarterly data sets containing all survey questions. They are made publicly available as databases to enable external users to access and produce their own analyses. They enable more detailed analysis but are published for calendar quarters only (quarter one refers to January to March, quarter two to April to June, and so on), and are not seasonally adjusted.

Since 2003, the LFS aggregate estimates or results have been 'interim-reweighted' every year. Interim-reweighting applies adjustments to the aggregate results to reflect how the latest available official population estimates compare with those used for weighting the microdata. This has amounted to an approximation of the effect that a full reweighting of the microdata would have. The aggregates were last interim-reweighted in December 2007 and reflect the current population estimates and projections.

The previous LFS microdata sets were weighted using population estimates published in 2003. Regular updates to these estimates meant that the LFS microdata had become increasingly out of date. This also meant that the published aggregates were not consistent with the LFS microdata used for more detailed analysis. Table 1 compares the levels and rates for the 
previously published aggregate estimates (interim-reweighted but not seasonally adjusted) with the equivalent estimates derived from the previous LFS microdata (pre-reweighting). The table shows that, in April to June 2007 for example, the total number of people in employment calculated from the microdata was around 600,000, or 2.3 per cent, lower than the equivalent aggregate estimate.

Reweighting of the microdata using the latest population estimates for all calendar quarters back to 1992 is now complete. As of 14 May 2008, the reweighted microdata are feeding through directly to the published LFS aggregate results; that is, the published aggregate estimates are based on, and consistent with, the reweighted LFS microdata. Interim-reweighting will not be required until the population estimates are next updated in summer 2008.

\section{Methodological developments}

Some small methodological enhancements have been made at the same time as the reweighting: a new calibration tool and a change to the population weighting method. This section will describe these changes and how they affect the published figures.

\section{New calibration tool}

Since the LFS is a continuous UK household sample survey, the responses reflect only a sample of the total population. These responses are weighted or calibrated to give estimates for the entire household population. Previously weighted LFS estimates were produced using a threestage population-weighting procedure. Full details are given in section 10 of the LFS User Guide Volume 1. ${ }^{1}$ To summarise briefly, each stage of the procedure corrected for a different cause of nonresponse: stage one corrected for nonresponse at a local authority level; stage two for non-response by age group and sex; and stage three for non-response by region, age group and sex. Each individual in the sample was assigned a weight via a complex iterative process that ensured the weighted estimates were in line (as much as is possible) with the official population estimates used for each of the three stages.

As part of the reweighting project, the statistical tool for carrying out the weighting has been replaced with

Table 1

\section{Differences between estimates obtained from LFS microdata (pre-reweighting) and LFS aggregate estimates interim-reweighted (previously published)}

Thousands, not seasonally adjusted, except where indicated

\begin{tabular}{|c|c|c|c|c|c|c|c|c|c|}
\hline & \multicolumn{9}{|c|}{ All people aged 16 and over } \\
\hline & $\begin{array}{r}\text { All aged } 16 \\
\text { and over }\end{array}$ & $\begin{array}{r}\text { Economically } \\
\text { active }\end{array}$ & In employment & Unemployed & $\begin{array}{r}\text { Economically } \\
\text { inactive }\end{array}$ & $\begin{array}{r}\text { Economic } \\
\text { activity } \\
\text { rate }(\%)\end{array}$ & $\begin{array}{r}\text { Employment } \\
\text { rate }(\%)\end{array}$ & $\begin{array}{r}\text { Unemployment } \\
\text { rate }(\%)\end{array}$ & $\begin{array}{r}\text { Economic } \\
\text { inactivity } \\
\text { rate }(\%)\end{array}$ \\
\hline \multicolumn{10}{|c|}{ LFS microdata ${ }^{1}$ (pre-reweighting) } \\
\hline Apr-Jun 1997 & 45,379 & 28,369 & 26,356 & 2,013 & 17,009 & 62.5 & 58.1 & 7.1 & 37.5 \\
\hline Apr-Jun 1999 & 45,679 & 28,571 & 26,876 & 1,695 & 17,108 & 62.5 & 58.8 & 5.9 & 37.5 \\
\hline Apr-Jun 2001 & 46,183 & 28,846 & 27,438 & 1,408 & 17,337 & 62.5 & 59.4 & 4.9 & 37.5 \\
\hline Apr-Jun 2002 & 46,438 & 29,073 & 27,617 & 1,456 & 17,365 & 62.6 & 59.5 & 5.0 & 37.4 \\
\hline Apr-Jun 2003 & 46,664 & 29,264 & 27,863 & 1,401 & 17,400 & 62.7 & 59.7 & 4.8 & 37.3 \\
\hline Apr-Jun 2004 & 46,912 & 29,393 & 28,024 & 1,368 & 17,519 & 62.7 & 59.7 & 4.7 & 37.3 \\
\hline Apr-Jun 2005 & 47,157 & 29,557 & 28,193 & 1,364 & 17,600 & 62.7 & 59.8 & 4.6 & 37.3 \\
\hline Apr-Jun 2006 & 47,409 & 29,942 & 28,339 & 1,604 & 17,466 & 63.2 & 59.8 & 5.4 & 36.8 \\
\hline Apr-Jun 2007 & 47,727 & 30,006 & 28,434 & 1,573 & 17,721 & 62.9 & 59.6 & 5.2 & 37.1 \\
\hline \multicolumn{10}{|c|}{ LFS aggregates interim-reweighted (previously published) } \\
\hline Apr-Jun 1997 & 45,509 & 28,468 & 26,443 & 2,024 & 17,042 & 62.6 & 58.1 & 7.1 & 37.4 \\
\hline Apr-Jun 1999 & 45,880 & 28,726 & 27,017 & 1,709 & 17,154 & 62.6 & 58.9 & 5.9 & 37.4 \\
\hline Apr-Jun 2001 & 46,441 & 29,057 & 27,636 & 1,420 & 17,384 & 62.6 & 59.5 & 4.9 & 37.4 \\
\hline Apr-Jun 2002 & 46,727 & 29,317 & 27,849 & 1,468 & 17,410 & 62.7 & 59.6 & 5.0 & 37.3 \\
\hline Apr-Jun 2003 & 47,016 & 29,551 & 28,134 & 1,417 & 17,466 & 62.9 & 59.8 & 4.8 & 37.1 \\
\hline Apr-Jun 2004 & 47,361 & 29,751 & 28,361 & 1,390 & 17,610 & 62.8 & 59.9 & 4.7 & 37.2 \\
\hline Apr-Jun 2005 & 47,787 & 30,055 & 28,659 & 1,395 & 17,732 & 62.9 & 60.0 & 4.6 & 37.1 \\
\hline Apr-Jun 2006 & 48,185 & 30,559 & 28,910 & 1,649 & 17,626 & 63.4 & 60.0 & 5.4 & 36.6 \\
\hline Apr-Jun 2007 & 48,590 & 30,705 & 29,083 & 1,622 & 17,886 & 63.2 & 59.9 & 5.3 & 36.8 \\
\hline \multicolumn{10}{|c|}{ Difference between results as shown ${ }^{2}$} \\
\hline Apr-Jun 1997 & 130 & 99 & 87 & 11 & 33 & 0.1 & - & - & -0.1 \\
\hline Apr-Jun 1999 & 201 & 155 & 141 & 14 & 46 & 0.1 & 0.1 & - & -0.1 \\
\hline Apr-Jun 2001 & 258 & 211 & 198 & 12 & 47 & 0.1 & 0.1 & - & -0.1 \\
\hline Apr-Jun 2002 & 289 & 244 & 232 & 12 & 45 & 0.1 & 0.1 & - & -0.1 \\
\hline Apr-Jun 2003 & 352 & 287 & 271 & 16 & 66 & 0.2 & 0.1 & - & -0.2 \\
\hline Apr-Jun 2004 & 449 & 358 & 337 & 22 & 91 & 0.1 & 0.2 & - & -0.1 \\
\hline Apr-Jun 2005 & 630 & 498 & 466 & 31 & 132 & 0.2 & 0.2 & - & -0.2 \\
\hline Apr-Jun 2006 & 776 & 617 & 571 & 45 & 160 & 0.2 & 0.2 & - & -0.2 \\
\hline Apr-Jun 2007 & 863 & 699 & 649 & 49 & 165 & 0.3 & 0.3 & 0.1 & -0.3 \\
\hline
\end{tabular}

\section{Notes:}

1 Comparable data are not available for 1998 and 2000.

2 Levels are rounded to the nearest thousand and rates are rounded to one decimal place.

- difference is zero 
something more robust and efficient. This is known as the Generalised Estimation System (GES) tool and was initially developed by Statistics Canada. The methodology employed by the GES tool is different from that used previously, in that it calibrates the data in a single process rather than numerous iterations over three stages. The two methodologies are asymptotically equivalent. In other words, they produce the same outcome providing the sample is sufficiently large, which, for the LFS, it invariably is. Consequently the impact on the LFS estimates caused by implementing the new weighting tool is very small. This outcome was also borne out by some testing using extracts of LFS data. In addition to providing improved statistical processing, the tool also provides diagnostic information to help assess data quality.

\section{Population weighting changes}

The LFS microdata have been reweighted using the latest mid-year population estimates for all calendar quarters back to 1992. In order to remain consistent with the LFS sample, the population estimates are adjusted to exclude those outside the coverage of the LFS. Consequently, communal establishments, apart from people living in National Health Service accommodation and students living in halls of residence who have a UKresident parent, are excluded from the LFS household population estimates.

Although the same set of population estimates had been used for the interimreweighting of the aggregate results as for the reweighting of the microdata, they had been applied differently. Under interimreweighting, the mid-year population estimate referred to the June to August three-month period. For the reweighting of the microdata, the May to July period was used. The LFS aggregates and microdata are now consistent with each other in this respect and use May to July as the period that relates to the mid-year population estimates. This methodological change has contributed to the revisions to the LFS aggregates published on 14 May 2008.

This change in the population weighting has meant that the population estimates used for the previously published aggregate estimates have been brought forward a month in relation to the LFS data. In other words, the population estimates that were used under interim-reweighting

\section{Figure 1}

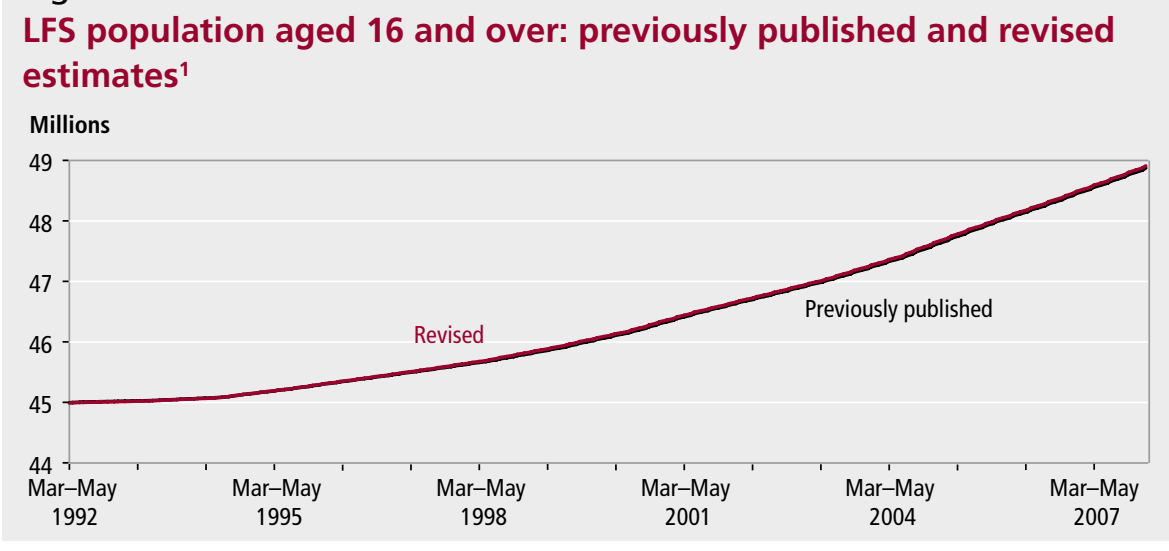

Note:

1 Dates represent rolling three-monthly periods.

\section{Figure 2}

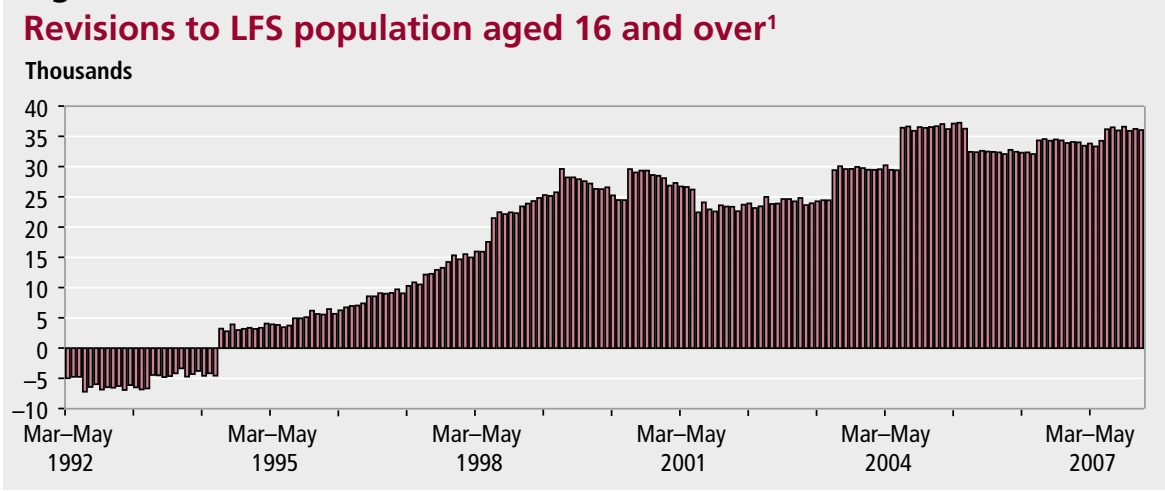

Note:

1 Dates represent rolling three-monthly periods.

for weighting the LFS data for June to August 2007 are now being used for weighting the LFS data for May to July 2007. Consequently, at the UK level, this results in upward revisions to the total population aged 16 and over, which are published alongside the LFS aggregates in the Labour Market Statistics First Release.

Figure 1 shows the population aged 16 and over used for weighting the interimreweighted series (previously published) and the population estimates used for reweighting the microdata. The lines represent the population levels and the bars in Figure 2 represent the revisions to the LFS population aged 16 and over.

As the closeness of the two lines suggests, the revisions to total LFS population aged 16 and over are small. These revisions reflect the change in the population weighting and affect all rolling three-monthly periods back to 1992. All are upwards since June to August 1994. The revisions are mostly in the region of 15,000 to 35,000 ; the largest are in July to September 2007 at 37,000 , or 0.1 per cent.

\section{Revisions to LFS national and regional aggregates}

The newly published LFS national and regional aggregate results have been subject to the following sources of revision:

- reweighted LFS microdata, using the latest population estimates

- change in population weighting method

- new calibration tool (GES), and

- recommendations from the review of seasonal adjustment

The first three sources of revision were applied simultaneously in producing a new aggregate time series. It was not possible to quantify the impacts of the three changes individually due to time and resource limitations. As mentioned earlier, the impact of the new calibration tool is neutral for the aggregate results.

The comparisons contained in this article are summarised in Box 1.

Table 1 was referred to earlier in the section that defines the LFS aggregate estimates and the microdata. It helps set the context of the LFS reweighting project and underlines the importance of regular reweighting of the LFS microdata.

Table 2 compares the aggregates derived from the reweighted LFS microdata and the previously published interim-reweighted aggregate estimates, before seasonal adjustment. The revisions to the reweighted NSA aggregates result from the reweighted 
Box 1

Assessment of the impact of revisions to the previously published LFS national and regional aggregate estimates and microdata

\begin{tabular}{llll}
\hline Table no. & Series $\mathbf{x}$ & Series $\mathbf{y}$ & Assessment \\
\hline 1 & Aggregate estimates derived from LFS & Interim-reweighted aggregate estimates, & The scale of the previous discrepancy \\
& microdata, prior to reweighting (NSA') & (previously published), NSA & $\begin{array}{l}\text { between LFS microdata and } \\
\text { interim-reweighted estimates }\end{array}$
\end{tabular}

$2 \quad$ Reweighted ${ }^{2}$ aggregate estimates derived from LFS microdata, NSA

Interim-reweighted aggregate
estimates (previously published), NSA

Interim reweighted aggregate estimates, SA, (previously published)

SA, ${ }^{3}$ after seasonal adjustment review (published 14 May).

$4 \quad$ Regional total population used to reweight microdata

5 Regional reweighted aggregate estimates, SA, after seasonal adjustment review (published 14 May)
Regional total population figures used in interim-reweighting (previously published)

Regional aggregate estimates
under interim-reweighting
(previously published)

Regional aggregate estimates (previously published)
The impact of reweighting on published NSA aggregate estimates, separate from any seasonal adjustment effects

The overall effect on the published aggregates, incorporating all sources of revision

The extent of the changes in the population estimates, by region

The overall effect on the published aggregates for each region, incorporating all sources of revision
Notes:
1 Not seasonally adjusted.
2 Estimates derived from reweighted LFS microdata.
3 Seasonally adjusted.

LFS microdata feeding through directly and also from the population weighting changes. The figures shown are for the three-month period ending June each year, back to 1992. All the headline economically active, inactive, unemployment and employment levels are showing revisions to the whole time series and are discussed in more detail below. Generally, since the population changes are included in both the numerator and denominator for the rate calculations, the revisions to the rates are small, ranging between -0.2 and +0.2 percentage points and, in many cases, zero. Any revisions that feed through to the rates at the UK level relate to changes caused by the reweighting of the microdata at the local authority level.

The LFS estimate of the number of people aged 16 and over who are economically active is the sum of those who are in employment and those who are unemployed. The revisions to this series are small, no greater than 0.1 per cent. The largest revisions are in November 2004 to January 2005 and November 2006 to January 2007 at about $+20,000$, or 0.1 per cent. For the economically inactive series, the revisions are all upwards from 1996 onwards. There are small revisions to the unemployment levels, no greater than $+/-0.2$ per cent. There are downward revisions in the more recent periods which are the result of the reweighted microdata. The revisions to the employment levels are all small, no greater than 0.1 per cent. The largest revisions are in December 2006 to
February 2007 at about $+22,000$, or 0.1 per cent.

The comparison shown in Table 2 was repeated on a seasonally adjusted basis, that is, taking account of the revised time series plus the historical effects of previous changes to the LFS seasonal adjustment parameters, which, until now, had not been applied to the whole time series. The differences arising from this comparison are very similar to the figures in Table 2. This means that the updated seasonal adjustment, as described above, did not change the figures significantly. In other words, the revisions to the interimreweighted aggregate estimates (seasonally adjusted) prior to the seasonal adjustment review were primarily due to the reweighting of the microdata, in particular the change to the population weighting method.

Impact of seasonal adjustment review For all series, except those measuring average hours worked and reasons for working part-time, the seasonal adjustment review recommended no changes to the current methods. Consequently, the differences between the reweighted LFS aggregates, before and after the seasonal adjustment review, are negligible. The changes made to the seasonal adjustment of the average hours worked, and reasons for working part-time series, are described in the section which follows titled 'Summary of LFS seasonal adjustment review 2008'.

Table 3 summarises the impact on the published UK level estimates. These aggregates have been subject to all four revision sources noted earlier in this article. The differences in this table are very similar to the differences noted in Table 2. This confirms that the reweighted microdata category (incorporating the population weighting changes) is the main contributor to the revisions to the LFS aggregates. The seasonal adjustment review is described in more detail below.

Table 4 summarises the impact of the reweighting and population weighting changes on the published Government Office Region population aged 16 and over. The figures shown are for the three-month period ending June each year, back to 1992. The revisions affect all rolling threemonthly periods back to 1992, and are all upwards since October to December 1997. None of the regions is affected particularly significantly by the revisions, with London and the South East showing the largest in terms of levels.

Table 5 summarises the differences between the interim-reweighted (previously published) estimates and the reweighted microdata, after implementation of the seasonal adjustment review recommendations, for the three-month period ending June 2007. The largest percentage change between the newly and previously published aggregates is for the number of people in employment for Yorkshire and The Humber: -1.4 per cent for April to June 2007. Overall, the impact of the reweighted microdata and seasonal 
Table 2

Differences between LFS aggregate estimates, interim-reweighted (previously published) and reweighted LFS microdata (not seasonally adjusted)

United Kingdom

Thousands, not seasonally adjusted, except where indicated

\begin{tabular}{|c|c|c|c|c|c|c|c|c|c|}
\hline & \multicolumn{8}{|c|}{ All people aged 16 and over } & \multirow[b]{2}{*}{$\begin{array}{r}\text { Economic } \\
\text { inactivity } \\
\text { rate }(\%)\end{array}$} \\
\hline & $\begin{array}{r}\text { All aged } 16 \\
\text { and over }\end{array}$ & $\begin{array}{r}\text { Economically } \\
\text { active }\end{array}$ & In employment & Unemployed & $\begin{array}{r}\text { Economically } \\
\text { inactive }\end{array}$ & $\begin{array}{r}\text { Economic } \\
\text { activity } \\
\text { rate }(\%)\end{array}$ & $\begin{array}{r}\text { Employment } \\
\text { rate }(\%)\end{array}$ & $\begin{array}{r}\text { Unemployment } \\
\text { rate }(\%)\end{array}$ & \\
\hline \multicolumn{10}{|c|}{ LFS aggregate estimates: reweighted LFS microdata ${ }^{1}$} \\
\hline Apr-Jun 1992 & 44,996 & 28,297 & 25,554 & 2,743 & 16,699 & 63.1 & 56.9 & 9.8 & 36.9 \\
\hline Apr-Jun 1993 & 45,022 & 28,138 & 25,241 & 2,898 & 16,884 & 62.5 & 56.1 & 10.3 & 37.5 \\
\hline Apr-Jun 1994 & 45,072 & 28,103 & 25,397 & 2,705 & 16,969 & 62.4 & 56.3 & 9.6 & 37.6 \\
\hline Apr-Jun 1995 & 45,205 & 28,129 & 25,711 & 2,418 & 17,076 & 62.2 & 56.9 & 8.6 & 37.8 \\
\hline Apr-Jun 1996 & 45,361 & 28,261 & 25,945 & 2,315 & 17,101 & 62.3 & 57.2 & 8.2 & 37.7 \\
\hline Apr-Jun 1997 & 45,520 & 28,470 & 26,444 & 2,026 & 17,050 & 62.5 & 58.1 & 7.1 & 37.5 \\
\hline Apr-Jun 1998 & 45,691 & 28,405 & 26,642 & 1,764 & 17,285 & 62.2 & 58.3 & 6.2 & 37.8 \\
\hline Apr-Jun 1999 & 45,905 & 28,733 & 27,023 & 1,710 & 17,172 & 62.6 & 58.9 & 6.0 & 37.4 \\
\hline Apr-Jun 2000 & 46,152 & 28,958 & 27,399 & 1,559 & 17,195 & 62.7 & 59.4 & 5.4 & 37.3 \\
\hline Apr-Jun 2001 & 46,467 & 29,066 & 27,643 & 1,423 & 17,402 & 62.6 & 59.5 & 4.9 & 37.5 \\
\hline Apr-Jun 2002 & 46,750 & 29,324 & 27,852 & 1,472 & 17,426 & 62.7 & 59.6 & 5.0 & 37.3 \\
\hline Apr-Jun 2003 & 47,041 & 29,552 & 28,132 & 1,420 & 17,489 & 62.8 & 59.8 & 4.8 & 37.2 \\
\hline Apr-Jun 2004 & 47,391 & 29,759 & 28,365 & 1,394 & 17,632 & 62.8 & 59.9 & 4.7 & 37.2 \\
\hline Apr-Jun 2005 & 47,824 & 30,062 & 28,665 & 1,397 & 17,761 & 62.9 & 59.9 & 4.6 & 37.1 \\
\hline Apr-Jun 2006 & 48,217 & 30,575 & 28,926 & 1,649 & 17,642 & 63.4 & 60.0 & 5.4 & 36.6 \\
\hline Apr-Jun 2007 & 48,624 & 30,721 & 29,100 & 1,621 & 17,903 & 63.2 & 59.8 & 5.3 & 36.8 \\
\hline \multicolumn{10}{|c|}{ LFS aggregate estimates: interim-reweighted (previously published) } \\
\hline Apr-Jun 1992 & 45,001 & 28,294 & 25,549 & 2,744 & 16,707 & 62.9 & 56.8 & 9.7 & 37.1 \\
\hline Apr-Jun 1993 & 45,029 & 28,136 & 25,236 & 2,900 & 16,893 & 62.5 & 56.0 & 10.3 & 37.5 \\
\hline Apr-Jun 1994 & 45,076 & 28,100 & 25,394 & 2,706 & 16,976 & 62.3 & 56.3 & 9.6 & 37.7 \\
\hline Apr-Jun 1995 & 45,201 & 28,125 & 25,710 & 2,415 & 17,076 & 62.2 & 56.9 & 8.6 & 37.8 \\
\hline Apr-Jun 1996 & 45,355 & 28,258 & 25,945 & 2,313 & 17,097 & 62.3 & 57.2 & 8.2 & 37.7 \\
\hline Apr-Jun 1997 & 45,509 & 28,468 & 26,443 & 2,024 & 17,042 & 62.6 & 58.1 & 7.1 & 37.4 \\
\hline Apr-Jun 1998 & 45,675 & 28,409 & 26,648 & 1,761 & 17,266 & 62.2 & 58.3 & 6.2 & 37.8 \\
\hline Apr-Jun 1999 & 45,880 & 28,726 & 27,017 & 1,709 & 17,154 & 62.6 & 58.9 & 5.9 & 37.4 \\
\hline Apr-Jun 2000 & 46,128 & 28,950 & 27,394 & 1,556 & 17,178 & 62.8 & 59.4 & 5.4 & 37.2 \\
\hline Apr-Jun 2001 & 46,441 & 29,057 & 27,636 & 1,420 & 17,384 & 62.6 & 59.5 & 4.9 & 37.4 \\
\hline Apr-Jun 2002 & 46,727 & 29,317 & 27,849 & 1,468 & 17,410 & 62.7 & 59.6 & 5.0 & 37.3 \\
\hline Apr-Jun 2003 & 47,016 & 29,551 & 28,134 & 1,417 & 17,466 & 62.9 & 59.8 & 4.8 & 37.1 \\
\hline Apr-Jun 2004 & 47,361 & 29,751 & 28,361 & 1,390 & 17,610 & 62.8 & 59.9 & 4.7 & 37.2 \\
\hline Apr-Jun 2005 & 47,787 & 30,055 & 28,659 & 1,395 & 17,732 & 62.9 & 60.0 & 4.6 & 37.1 \\
\hline Apr-Jun 2006 & 48,185 & 30,559 & 28,910 & 1,649 & 17,626 & 63.4 & 60.0 & 5.4 & 36.6 \\
\hline Apr-Jun 2007 & 48,590 & 30,705 & 29,083 & 1,622 & 17,886 & 63.2 & 59.9 & 5.3 & 36.8 \\
\hline
\end{tabular}

Difference between results as shown ${ }^{2}$

\begin{tabular}{|c|c|c|c|}
\hline Apr-Jun 1992 & -5 & 3 & 5 \\
\hline Apr-Jun 1993 & -7 & 2 & 5 \\
\hline Apr-Jun 1994 & -4 & 3 & 3 \\
\hline Apr-Jun 1995 & 4 & 4 & 1 \\
\hline Apr-Jun 1996 & 6 & 3 & - \\
\hline Apr-Jun 1997 & 11 & 2 & 1 \\
\hline Apr-Jun 1998 & 16 & -4 & -6 \\
\hline Apr-Jun 1999 & 25 & 7 & 6 \\
\hline Apr-Jun 2000 & 24 & 8 & 5 \\
\hline Apr-Jun 2001 & 26 & 9 & 7 \\
\hline Apr-Jun 2002 & 23 & 7 & 3 \\
\hline Apr-Jun 2003 & 25 & 1 & -2 \\
\hline Apr-Jun 2004 & 30 & 8 & 4 \\
\hline Apr-Jun 2005 & 37 & 7 & 6 \\
\hline Apr-Jun 2006 & 32 & 16 & 16 \\
\hline Apr-Jun 2007 & 34 & 16 & 17 \\
\hline
\end{tabular}

-1
-2
-1
3
2
2
3
1
3
3
4
3
4
2
-
-1

$\begin{array}{rr}-8 & \\ -9 & \\ -7 & \\ - & \\ 4 & \\ & \\ 8 & \\ 19 & \\ 18 & \\ 17 & \\ 18 & \\ & \\ 16 & \\ 23 & \\ 22 & \\ 29 & \\ 16 & \\ 17 & \end{array}$

$\begin{array}{rrrr}0.2 & 0.1 & 0.1 & -0.2 \\ - & 0.1 & - & - \\ 0.1 & - & - & -0.1 \\ - & - & - & - \\ - & - & - & - \\ -0.1 & & - & 0.1 \\ - & - & - & - \\ - & - & 0.1 & - \\ -0.1 & - & - & 0.1 \\ - & - & - & 0.1 \\ & - & - & - \\ - & - & - & - \\ -0.1 & - & - & 0.1 \\ - & - & - & - \\ - & -0.1 & - & - \\ - & - & - & - \\ - & -0.1 & - & -\end{array}$

\section{Notes:}

1 Estimates derived from reweighted microdata.

2 Levels are rounded to the nearest thousand and rates are rounded to one decimal place.

- difference is zero 
Table 3

Differences between LFS aggregate estimates, interim-reweighted (previously published) and reweighted LFS microdata, after seasonal adjustment review

United Kingdom

Thousands, seasonally adjusted, except where indicated

\begin{tabular}{|c|c|c|c|c|c|c|c|c|c|}
\hline & \multicolumn{9}{|c|}{ All people aged 16 and over } \\
\hline & $\begin{array}{l}\text { All aged } 16 \\
\text { and over }\end{array}$ & $\begin{array}{r}\text { Economically } \\
\text { active }\end{array}$ & In employment & Unemployed & $\begin{array}{r}\text { Economically } \\
\text { inactive }\end{array}$ & $\begin{array}{r}\text { Economic } \\
\text { activity } \\
\text { rate }(\%)\end{array}$ & $\begin{array}{r}\text { Employment } \\
\text { rate }(\%)\end{array}$ & $\begin{array}{r}\text { Unemployment } \\
\text { rate }(\%)\end{array}$ & $\begin{array}{r}\text { Economic } \\
\text { inactivity } \\
\text { rate }(\%)\end{array}$ \\
\hline \multicolumn{10}{|c|}{ LFS aggregate estimates: reweighted LFS microdata, ${ }^{1}$ after seasonal adjustment review } \\
\hline Apr-Jun 1992 & 44,996 & 28,379 & 25,601 & 2,778 & 16,617 & 63.1 & 56.9 & 9.8 & 36.9 \\
\hline Apr-Jun 1993 & 45,022 & 28,220 & 25,288 & 2,932 & 16,802 & 62.7 & 56.2 & 10.4 & 37.3 \\
\hline Apr-Jun 1994 & 45,072 & 28,184 & 25,448 & 2,736 & 16,888 & 62.5 & 56.5 & 9.7 & 37.5 \\
\hline Apr-Jun 1995 & 45,205 & 28,212 & 25,768 & 2,444 & 16,992 & 62.4 & 57.0 & 8.7 & 37.6 \\
\hline Apr-Jun 1996 & 45,361 & 28,348 & 26,009 & 2,339 & 17,013 & 62.5 & 57.3 & 8.3 & 37.5 \\
\hline Apr-Jun 1997 & 45,520 & 28,564 & 26,514 & 2,050 & 16,956 & 62.7 & 58.2 & 7.2 & 37.3 \\
\hline Apr-Jun 1998 & 45,691 & 28,506 & 26,715 & 1,791 & 17,185 & 62.4 & 58.5 & 6.3 & 37.6 \\
\hline Apr-Jun 1999 & 45,905 & 28,840 & 27,097 & 1,743 & 17,065 & 62.8 & 59.0 & 6.0 & 37.2 \\
\hline Apr-Jun 2000 & 46,152 & 29,069 & 27,469 & 1,600 & 17,084 & 63.0 & 59.5 & 5.5 & 37.0 \\
\hline Apr-Jun 2001 & 46,467 & 29,176 & 27,706 & 1,470 & 17,291 & 62.8 & 59.6 & 5.0 & 37.2 \\
\hline Apr-Jun 2002 & 46,750 & 29,433 & 27,911 & 1,521 & 17,317 & 63.0 & 59.7 & 5.2 & 37.0 \\
\hline Apr-Jun 2003 & 47,041 & 29,659 & 28,191 & 1,468 & 17,382 & 63.0 & 59.9 & 5.0 & 37.0 \\
\hline Apr-Jun 2004 & 47,391 & 29,867 & 28,428 & 1,439 & 17,524 & 63.0 & 60.0 & 4.8 & 37.0 \\
\hline Apr-Jun 2005 & 47,824 & 30,170 & 28,732 & 1,438 & 17,653 & 63.1 & 60.1 & 4.8 & 36.9 \\
\hline Apr-Jun 2006 & 48,217 & 30,686 & 28,998 & 1,687 & 17,531 & 63.6 & 60.1 & 5.5 & 36.4 \\
\hline Apr-Jun 2007 & 48,624 & 30,832 & 29,174 & 1,658 & 17,792 & 63.4 & 60.0 & 5.4 & 36.6 \\
\hline \multicolumn{10}{|c|}{ LFS aggregates interim-reweighted (previously published) } \\
\hline Apr-Jun 1992 & 45,001 & 28,376 & 25,597 & 2,780 & 16,624 & 63.1 & 56.9 & 9.8 & 36.9 \\
\hline Apr-Jun 1993 & 45,029 & 28,218 & 25,284 & 2,934 & 16,811 & 62.7 & 56.2 & 10.4 & 37.3 \\
\hline Apr-Jun 1994 & 45,076 & 28,181 & 25,445 & 2,737 & 16,895 & 62.5 & 56.4 & 9.7 & 37.5 \\
\hline Apr-Jun 1995 & 45,201 & 28,208 & 25,767 & 2,441 & 16,993 & 62.4 & 57.0 & 8.7 & 37.6 \\
\hline Apr-Jun 1996 & 45,355 & 28,345 & 26,009 & 2,336 & 17,010 & 62.5 & 57.3 & 8.2 & 37.5 \\
\hline Apr-Jun 1997 & 45,509 & 28,561 & 26,513 & 2,048 & 16,949 & 62.8 & 58.3 & 7.2 & 37.2 \\
\hline Apr-Jun 1998 & 45,675 & 28,509 & 26,721 & 1,788 & 17,166 & 62.4 & 58.5 & 6.3 & 37.6 \\
\hline Apr-Jun 1999 & 45,880 & 28,833 & 27,090 & 1,743 & 17,047 & 62.8 & 59.0 & 6.0 & 37.2 \\
\hline Apr-Jun 2000 & 46,128 & 29,061 & 27,461 & 1,599 & 17,067 & 63.0 & 59.5 & 5.5 & 37.0 \\
\hline Apr-Jun 2001 & 46,441 & 29,167 & 27,694 & 1,472 & 17,274 & 62.8 & 59.6 & 5.0 & 37.2 \\
\hline Apr-Jun 2002 & 46,727 & 29,422 & 27,906 & 1,516 & 17,305 & 63.0 & 59.7 & 5.2 & 37.0 \\
\hline Apr-Jun 2003 & 47,016 & 29,656 & 28,192 & 1,464 & 17,361 & 63.1 & 60.0 & 4.9 & 36.9 \\
\hline Apr-Jun 2004 & 47,361 & 29,857 & 28,423 & 1,434 & 17,504 & 63.0 & 60.0 & 4.8 & 37.0 \\
\hline Apr-Jun 2005 & 47,787 & 30,163 & 28,727 & 1,435 & 17,624 & 63.1 & 60.1 & 4.8 & 36.9 \\
\hline Apr-Jun 2006 & 48,185 & 30,670 & 28,983 & 1,687 & 17,515 & 63.7 & 60.2 & 5.5 & 36.3 \\
\hline Apr-Jun 2007 & 48,590 & 30,814 & 29,153 & 1,661 & 17,776 & 63.4 & 60.0 & 5.4 & 36.6 \\
\hline
\end{tabular}

Difference between results as shown ${ }^{2}$

Apr-Jun 1992

Apr-Jun 1993

Apr-Jun 1994

Apr-Jun 1995

Apr-Jun 1996

-5
-7
-4
4
6

Apr-Jun 1997

Apr-Jun 1998

Apr-Jun 1999

Apr-Jun 2000

Apr-Jun 2001

30,814

29,153

1,661

17,776

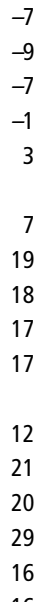

-7
-9
-7
-1
3

7
7
19
18
17
17

12
21
20
29
16
16

$-0.1$

$\begin{array}{rrr}- & - & - \\ - & - & - \\ 0.1 & - & - \\ - & - & - \\ - & 0.1 & - \\ -0.1 & - & 0.1 \\ - & - & - \\ - & - & - \\ - & - & - \\ - & - & - \\ & - & - \\ - & -1 & 0.1 \\ -0.1 & - & - \\ - & - & - \\ - & - & 0.1 \\ -0.1 & - & - \\ - & & \end{array}$

\section{Notes:}

1 Estimates derived from reweighted LFS microdata.

2 Levels are rounded to the nearest thousand and rates are rounded to one decimal place.

- difference is zero 
Table 4

Differences between LFS regional population estimates, interim-reweighted (previously published) and reweighted LFS microdata

United Kingdom

Thousands

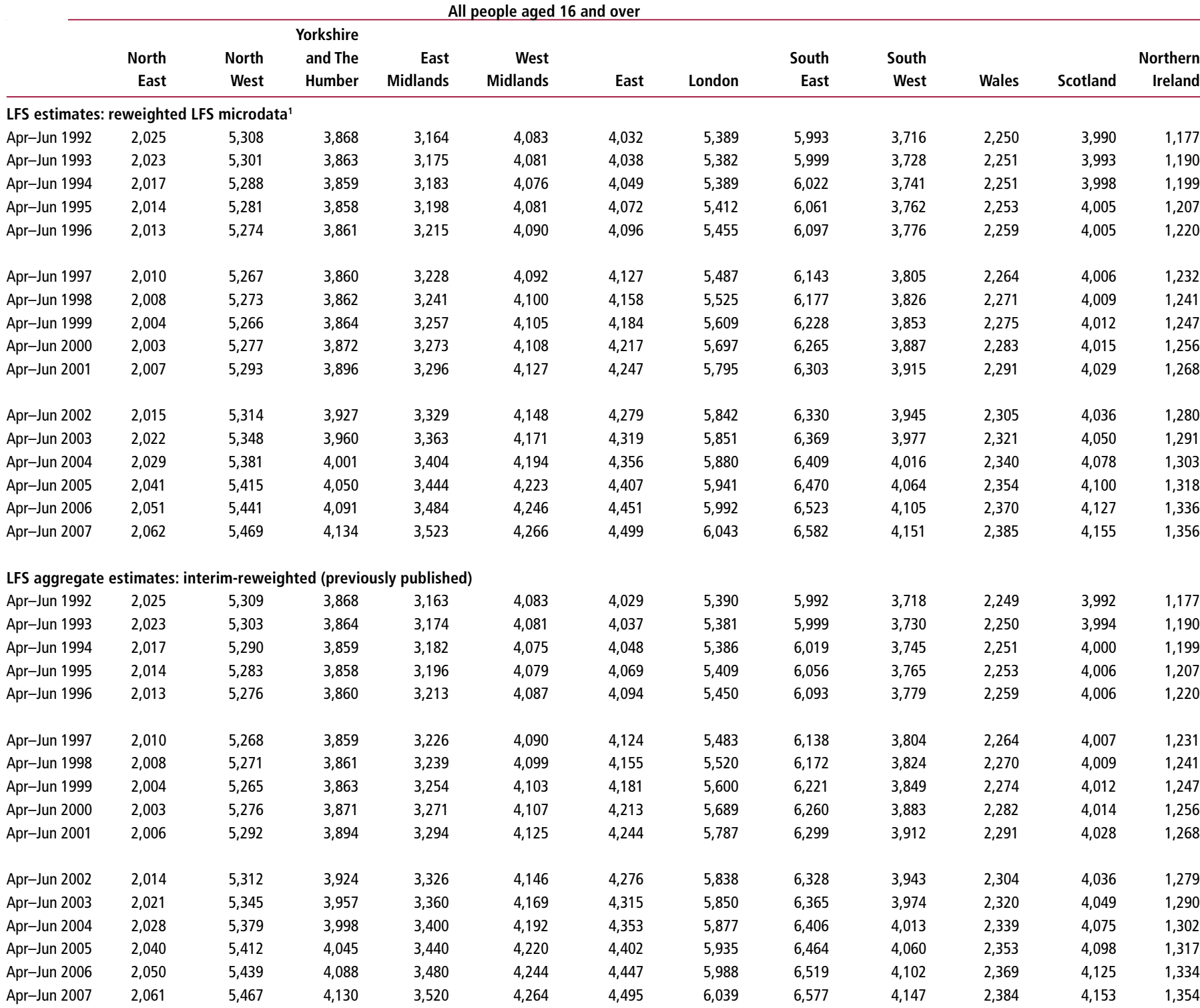

Difference between results as shown ${ }^{2}$

Apr-Jun 1993

Apr-Jun 1994

Apr-Jun 1995

$-2$

Apr-Jun 1997

Apr-Jun 1998

Apr-Jun 1999

Apr-Jun 2000

Apr-Jun 2001

6,577

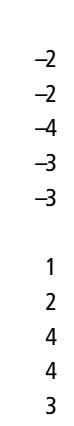

Apr-Jun 2002

Apr-Jun 2003

Apr-Jun 2004

Apr-Jun 2005

Apr-Jun 2006

Apr-Jun 2007

$n^{2}$
-1
-2
-2
-2
-2
-1
2
1
1
1

-
-1
-
-
1

3
1
1
3
2
3
3
3
4
3

-1
1
3
3
5

4
5
9
8
8

\begin{tabular}{lllll}
1 & -2 & 1 & -2 & - \\
- & -2 & 1 & -1 & - \\
3 & -4 & - & -2 & - \\
5 & -3 & - & -1 & - \\
4 & -3 & - & -1 & - \\
5 & 1 & - & -1 & 1 \\
5 & 2 & 1 & - & - \\
7 & 4 & 1 & - & - \\
5 & 4 & 1 & 1 & - \\
4 & 3 & - & 1 & - \\
& & & & \\
2 & 2 & 1 & - & 1 \\
4 & 3 & 1 & 1 & 1 \\
3 & 3 & 1 & 3 & 1 \\
6 & 4 & 1 & 2 & 1 \\
4 & 3 & 1 & 2 & 2 \\
5 & 4 & 1 & 2 & 2 \\
\hline
\end{tabular}

\section{Notes:}

1 Estimates derived from reweighted LFS microdata.

2 Levels are rounded to the nearest thousand.

- difference is zero 
adjustment on the LFS regional published aggregates is small.

\section{Summary of LFS seasonal adjustment review 2008}

A comprehensive review of the seasonal adjustment of all aggregate results published in the monthly national and regional Labour Market Statistics First Releases was carried out in March 2008. This included an examination of any changes in seasonality and the identification of any reasons for unusual patterns. The settings for the seasonal adjustment process were also reviewed, for example, the choice of model and the types of moving averages used for estimating the trend and seasonal components. The time period covered was 1992 to 2007 inclusive.

LFS seasonal adjustment has been carried out in the past using the standard international tool X-11 Arima. Following this review, the latest version of this tool, $\mathrm{X}-12$ Arima, has now been embedded into the production process for the LFS aggregate results. This has led to improved efficiency and greater flexibility when producing the seasonally adjusted figures. The implementation of the new tool itself has not caused any revisions to the LFS results.

For all series except those measuring average hours worked and reasons for

Table 5

Differences between LFS regional aggregate estimates, interim-reweighted (previously published) and reweighted LFS microdata, after seasonal adjustment review, April to June 2007

Thousands, seasonally adjusted, except where indicated

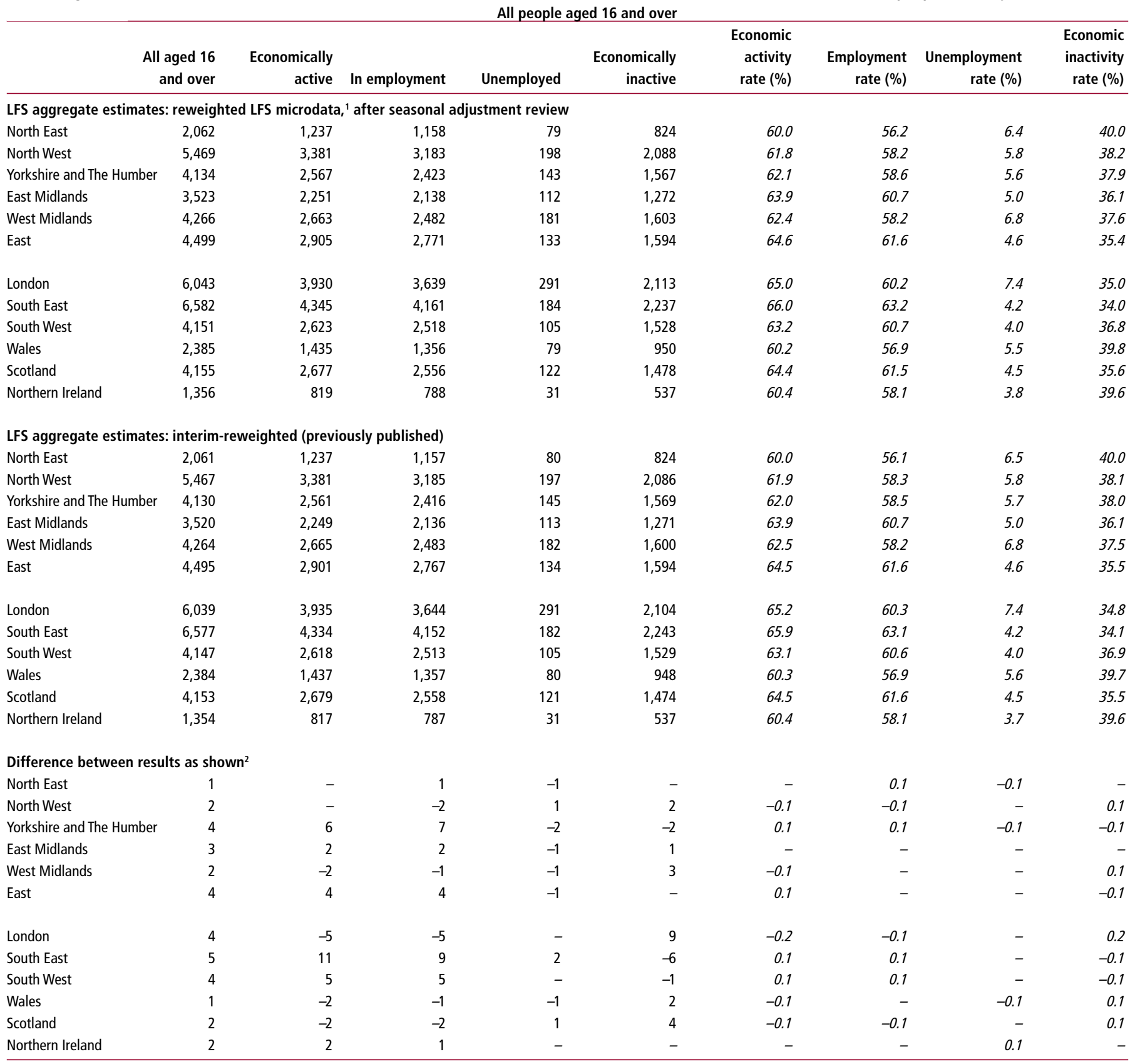

\section{Notes:}

1 Estimates derived from reweighted LFS microdata.

2 Levels are rounded to the nearest thousand and rates are rounded to one decimal place.

- difference is zero 
part-time work, the review recommended no changes to the method of seasonal adjustment. Consequently, any revisions arising from this review are mostly very small and are the result of more, and updated, data feeding into the seasonal adjustment. In addition, though, the opening up of the time series back to 1992 for revisions has meant that some recommendations from previous reviews of LFS seasonal adjustment have now fed through to published results. At previous reviews, only the three latest years were opened up to revision. These additional historical revisions are also mostly very small.

The revisions resulting from the seasonal adjustment review generally have very little impact on the headline LFS series, as indicated in the previous section. The series that require comment are discussed in more detail below.

\section{Reasons for working part-time}

Reasons for working part-time (Table 3 of the Labour Market Statistics First Release) classifies those who are employed part-time by the reasons they give for not working full-time. The published breakdowns consist of 'could not find full-time job', 'did not want full-time job, 'ill or disabled' and 'student or at school'.

Historically, all the above published seasonally adjusted figures have been constrained to the total of part-time workers by reason. However, this calculation did not include the answer 'no reason given', which although unpublished, has been used to derive the total before seasonal adjustment. As a result, each reason has been scaled up or down by slightly more than it should have been.

Changing the constraining methodology to include the 'no reason given' series means that additivity appears to be lost when comparing the published series with the total (the 'no reason given' category is neither published nor seasonally adjusted as it is regarded as too small to do so). The overall effect is minimal and it now means that the seasonally adjusted estimates for each reason are fully consistent with the not seasonally adjusted estimates, which are also publicly available.

\section{Average hours worked}

Changes to the seasonal adjustment method were recommended for the series in Table 7 of the Labour Market Statistics First Release, that is, the average actual weekly hours of work. These statistics measure the number of hours actually worked by respondents during the week surveyed. They are affected directly by changes in the number of hours individuals work, in particular those caused by time off due to holidays. A number of 'calendar effects' related to holiday periods can cause distortions to the seasonal adjustment of the actual hours worked series. These are:

- late May bank holiday - which falls in either the May or June survey period

- August bank holiday - which falls in either the August or September survey period

- Easter - which usually falls in either March or April, and sometimes affects the May survey period

- Christmas - which falls in either the December or January survey period, or sometimes straddles both

LFS historical data are used to model the impact of the calendar effects. Permanent prior adjustments are then derived from that analysis and are used to remove the calendar effects during the seasonal

\section{Figure 3}

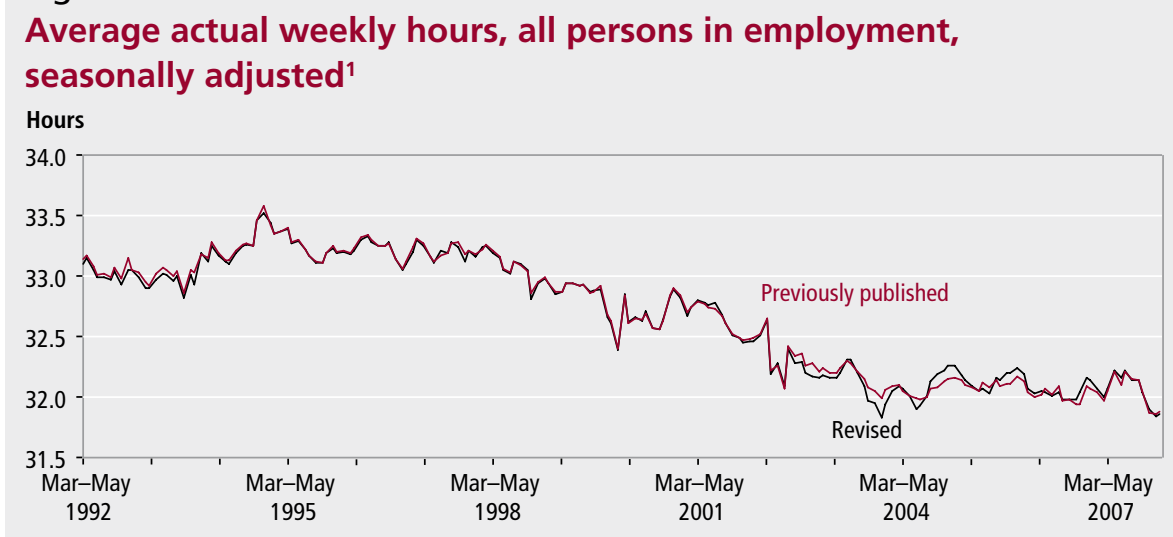

Note:

1 Dates represent rolling three-monthly periods. 


\section{Conclusions and next steps}

This article has presented analysis on the impact of full reweighting and the implementation of recommendations from the latest seasonal adjustment review on the LFS aggregates and microdata. The revisions to the national and regional levels are mostly less than 0.1 per cent and the revisions to the rates are mostly zero, with just a few at 0.1 percentage points. The results show that the LFS aggregates are not affected significantly by the revisions. This also shows that the interim-reweighting of the LFS aggregate estimates has been effective at approximating the impact of fully reweighted microdata.

ONS aims to ensure that its published LFS estimates continue to be kept closely in line with the latest published population estimates. Future revised population estimates will be incorporated into the revised LFS series using the interim LFS adjustment procedure as appropriate. Full reweighting for future years will depend on the extent of revisions to official population estimates and availability of resources.

\section{Notes}

1 See www.statistics.gov.uk/downloads/ theme_labour/lfsug_vol1_2007.pdf

\section{CONTACT}

国elmr@ons.gsi.gov.uk 